7 Hamada N, Kuwano K, Yamada M, et al. Anti-vascular endothelial growth factor gene therapy attenuates lung injury and fibrosis in mice. J Immunol 2005; 175: 1224-1231.

8 Feghali-Bostwick CA, Gadgil AS, Otterbein LE, et al. Autoantibodies in patients with chronic obstructive pulmonary disease. Am J Respir Crit Care Med 2008; 177: 156-163.
9 Selman M, Pardo A. Role of epithelial cells in idiopathic pulmonary fibrosis: from innocent targets to serial killers. Proc Am Thorac Soc 2006; 3: 364-372.

\title{
Pre-immigration screening for pulmonary tuberculosis: the unanswered questions
}

\section{To the Editors:}

In a recent issue of the European Respiratory Journal, the article by Mor et al. [1] captured my interest. The results are no doubt promising but there are some points of concern that need to be highlighted.

Firstly, in a country such as Ethiopia, where there is a very high incidence of pulmonary tuberculosis (PTB), screening for latent tuberculosis infection (LTBI) by tuberculin skin test (TST) is not justified. This is because such a strategy has many limitations. The main problem is that of the sensitivity and specificity of TST. In immunocompromised persons, particularly those with HIV infection, the sensitivity is markedly reduced and the possibility of missing the diagnosis of tuberculosis is always there [2]. In addition, there is the problem of false-positive reactions as infections with nontuberculous mycobacteria are highly prevalent in countries where tuberculosis is common [3]. Bacille Calmette-Guérin (BCG) vaccination is usually routinely given in newborns and schoolchildren in such countries and this may again lead to false-positive tuberculin reactions. Nearly one-third to one-half of all positive TST results among immigrants from countries with high and intermediate rates of tuberculosis are due to BCG vaccination $[4,5]$ and nontuberculous mycobacteria $[4,6]$.

In such circumstances, early detection and prompt treatment of active PTB cases is more justifiable than screening for LTBI.

Secondly, the reliability of chest radiography, used as a tool for screening in the study of Mor et al. [1] is still questionable. Persons with normal chest radiography may have active PTB [7], and even persons with chest radiography showing shadows suggestive of PTB may in reality not have active tuberculosis. Moreover, other factors such as poor quality of the chest radiograph and wide inter-observer variations [8] in the interpretation of chest radiographs may lead to misdiagnosis. False-negative diagnoses may pose a threat to public health through the spread of tuberculosis, whereas falsepositive diagnoses will result in inefficient use of resources. Misdiagnosis of active tuberculosis as latent infection and subsequent use of single-drug chemoprophylaxis may result in drug resistance. As well, there is also the radiation hazard involved in performing chest radiography on all the immigrants. It is well known that radiation generates highly reactive free radicals and is carcinogenic, teratogenic and mutagenic. It has been associated with cancers of the thyroid, bone, lung, breast and leukocytes [9]. Like lead and asbestos, radiation has no safe threshold. Therefore, it would be wise to avoid all unwarranted exposure to ionising radiation, no matter how little it may be. So performing chest radiography in only those persons who have symptoms suggestive of PTB seems to be a more pragmatic approach, rather than using it as a screening method in a resource-constrained country such as Ethiopia.

Finally, the point that needs to be highlighted here is that the test for HIV should have been done in all immigrants in Ethiopia itself, not after reaching Israel. It is well known that HIVinfected persons usually have atypical presentations of PTB, both clinically as well as radiologically, and that these persons are less likely to be sputum smear-positive [10], though they may be harbouring active tuberculosis. TST in these persons is considered as positive even if the induration is $\geqslant 5 \mathrm{~mm}$. Therefore, HIV testing for all persons before they reached Israel would have helped in better assessment of LTBI and to decide who the real candidates for chemoprophylaxis were and which were to get active treatment with antituberculosis drugs.

In a country with a high incidence of pulmonary tuberculosis, the prevalence of isoniazid resistance is also expected to be high. Thus, administration of a single drug for chemoprophylaxis should be done more judiciously, especially when the epidemic of multi-drug resistant tuberculosis is at its peak and the threat of extensively drug resistant tuberculosis is hovering over us.

\section{S. Bhuniya}

Chest Medicine, R. G. Kar Medical College and Hospital, Kolkata, India.

\section{STATEMENT OF INTEREST}

None declared.

\section{REFERENCES}

1 Mor Z, Lerman Y, Leventhal A. Pre-immigration screening process and pulmonary tuberculosis among Ethiopian migrants in Israel. Eur Respir J 2008; 32: 413-418.

2 Graham NMH, Nelson KE, Solomon L, et al. Prevalence of tuberculin positivity and skin test anergy in HIV-1 seropositive and seronegative intravenous drug users. JAMA 1992; 267: 369-373.

3 Kardjito T, Beck JS, Grange JM, Stanford JL. A comparision of the responsiveness to four new tuberculins among Indonesian patients with pulmonary tuberculosis and healthy subjects. Eur J Respir Dis 1986; 69: 142-145. 
4 Menzies RI, Vissandjee B, Amyot D. Factors associated with tuberculin reactivity among the foreign-born in Montreal. Am Rev Respir Dis 1992; 146: 752-756.

5 Menzies RI, Vissandjee B, Rocher I, St Germain Y. The booster effect in two-step tuberculin testing among young adults in Montreal. Ann Intern Med 1994; 120: 190-198.

6 Palmer CE, Edwards LB, Hopwood L, Edwards PQ. Experimental and epidemiologic basis for the interpretation of tuberculin sensitivity. J Pediatr 1959; 55: 413-428.

7 Marciniuk DD, McNab BD, Martin WT, Hoeppner VH. Detection of pulmonary tuberculosis in patients with a normal chest radiograph. Chest 1999; 115: 445-452.
8 Shaw NJ, Hendry M, Eden OB. Inter-observer variation in interpretation of chest x-rays. Scott Med J 1990; 35: 140-141.

9 Radiation injury. In: Beers M, Porter R, Jones T, et al., eds. The Merck Manual of Diagnosis and Therapy. 18th Edn. White-house Station, Merck Research Laboratories, 2006; pp. 2601-2609.

10 Getahun H, Harrington M, O'Brien R, Nunn P. Diagnosis of smear-negative pulmonary tuberculosis in people with HIV infection or AIDS in resource-constrained settings: informing urgent policy changes. Lancet 2007; 369: 2042-2049.

DOI: 10.1183/09031936.00141008 